\title{
Micro-stratigraphical investigation on corrosion layers in ancient Bronze artefacts by scanning electron microscopy energy dispersive spectrometry and optical microscopy
}

\author{
Omid Oudbashi ${ }^{1 *}$, Seyed Mohammadamin Emami ${ }^{1}$, Hossein Ahmadi ${ }^{1}$ and Parviz Davami ${ }^{2}$
}

\begin{abstract}
Background: Archaeological metallic artefacts buried in soils deteriorate by means of various environmental as well as internal factors and mechanisms over time such as change in composition and microstructure of metal and corrosive factors due to long-term burial environment. Corrosion in metals occurs in different morphologies and results in different types of corrosion products based on soil composition. Identification of corrosion mechanisms and morphology in archaeological metals can help conservators to characterize deterioration occurred in metals and make decisions to protect artefacts about preventing further deterioration. In archaeological bronzes, different layers may form on the surface of artefacts and their composition, depth and shape depends on factors noted above.
\end{abstract}

Results: In this paper, results of investigation carried out on ancient bronzes discovered from Haft Tappeh archaeological site, southwestern Iran, are presented. The ancient bronze samples are dated to the Middle Elamite period about 14th century BC. Some of the Haft Tappeh bronze artefacts corroded completely and a multilayer structure has formed. To study the stratigraphy of corrosion layers and their composition, some bronze artefacts have been analyzed using SEM-EDS (Scanning Electron Microscopy Energy Dispersive Spectrometry) and Optical Microscopy analyses. The results show difference between the amount of $\mathrm{Cu}$ and $\mathrm{Sn}$ in layers that may follow from copper leaching from inner layers and formation of copper trihydroxychlorides because of bronze disease.

Conclusions: Based on the results, it can be concluded that SEM-EDS analysis and Microscopy observations can help to characterize compositional difference between corrosion layers in the micro scale as well as corrosion mechanisms occurring in archaeological metal artefacts.

Keywords: Archaeological bronzes, Corrosion stratigraphy, SEM-EDS, Copper leaching, Copper trihydroxychlorides

\section{Introduction}

The long term burial conditions in soil causes various corrosion morphologies in archaeological metals, from a thin corrosion layer to a completely corroded and mineralized artefact $[1,2]$. In recent years, valuable studies have been performed to characterize changes occurring in archaeological metals to understand their corrosion mechanism and morphology as well as conservation conditions [3-8].

\footnotetext{
* Correspondence: o.oudbashi@aui.ac.ir

${ }^{1}$ Faculty of Conservation, Art University of Isfahan, Isfahan, Iran Full list of author information is available at the end of the article
}

One of the main corrosion morphologies in ancient bronzes is layered morphology which is observed in some bronze artefacts from Haft Tappeh Middle Elamite site, southwest Iran, belonging to about the 14th century BC $[9,10]$. The completely corroded artefacts show a layered structure in which the central layer consists of a white-grayish phase that is covered with different layers in red, black and green. The composition of the central layer in some samples has been studied previously by SEM-EDAX analysis [9], but to better understand other corrosion layers, the relationship between layers, chemical composition differences in layers and corrosion 


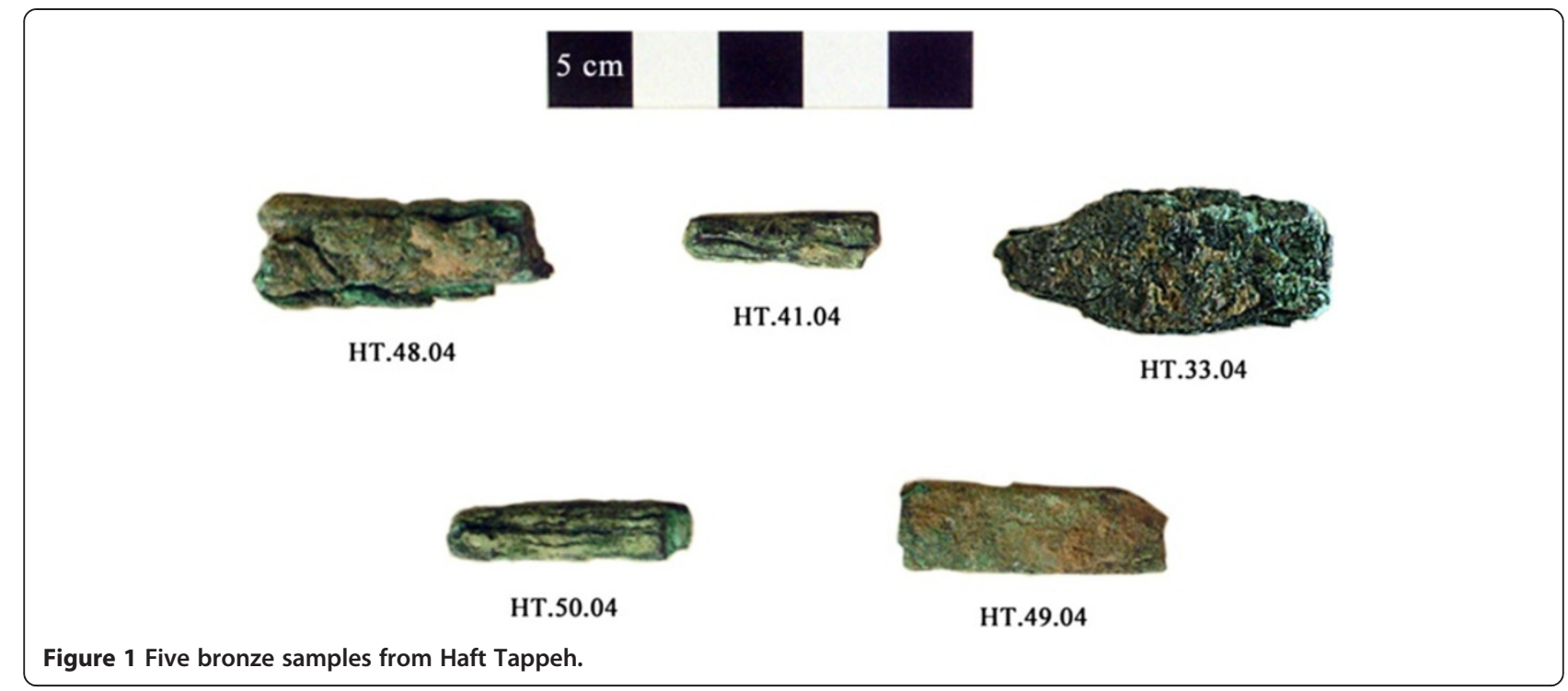

mechanism in these bronzes; in this paper we report a detailed stratigraphical investigation using SEM-EDS observation and analysis, as well as optical microscopy (OM).

\section{Experimental}

To study the stratigraphy and chemical composition analysis of corrosion layers in some Haft Tappeh bronze artefacts, five metallic samples from completely corroded artefacts were selected for experiments (Figure 1). The selected samples belong to the bronze collection from excavations carried out by E. O. Negahban from 1965 to 1978 [11] that are now maintained in the Haft Tappeh museum.
The selected samples were mounted in epoxy resin in room temperature and ground by abrasive silicon carbide papers from 120, 240, 400, 800, 1200 and 2000 grade respectively. Because of the samples were completely corroded, polishing with diamond powder was omitted. Then, corrosion layers were analyzed by the SEM-EDS semi-quantitative carried out at the SEM laboratory, Razi Metallurgical Research Center, Tehran on mounted samples in order to observe and analyze details of microstructure. The SEM analyses were performed on the TESCAN model VEGA II XMU in low vacuum, with a RONTEC backscattered electrons detector (BSE) and an energy dispersive spectrometer (EDS). In addition, corrosion layers were observed in
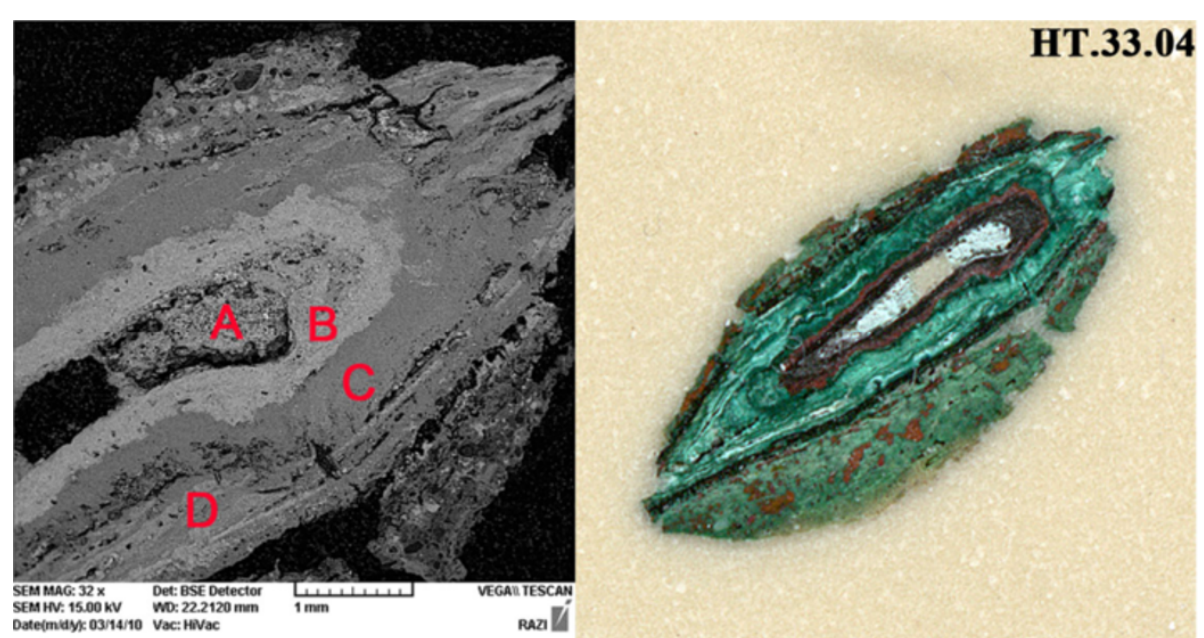

Figure 2 Cross section and SEM-BSE micrograph of sample HT.33.04. The multilayer structure and white-grayish phase can be visible. The SEM-EDS analysis areas are characterized. 


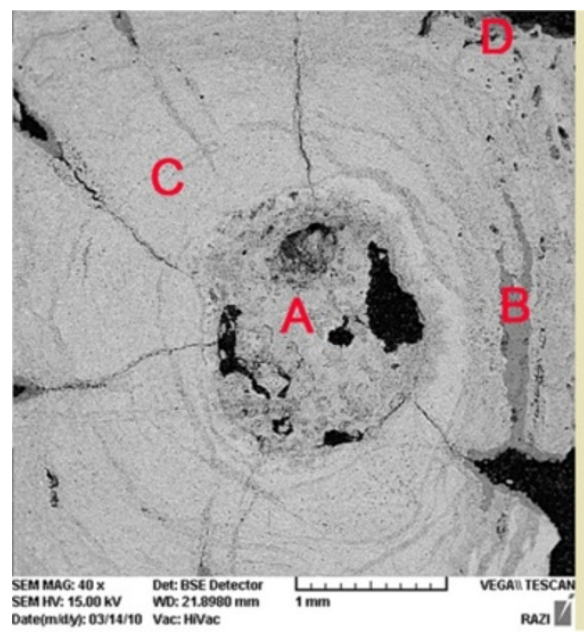

\section{HT.41.04}

Figure 3 Cross section and SEM-BSE micrograph of sample HT.41.04 with analysis areas. The multilayer structure of red-brown huge corrosion phase and white-grayish phase are visible.

mounted samples using a polarized light microscope BK-POL/BKPOLR model manufactured by Alltion Company in dark field, at Faculty of Conservation, Art University of Isfahan.

\section{Results and discussion}

The cross section of samples and corrosion layers observed by SEM method are shown in Figures 2, 3, 4, 5 and 6. A white-grayish phase is visible in center of all samples which is surrounded by various layers of black, red and green corrosion products. The corrosion products have a multilayer microstructure that can be observed in cross section and optical microscopy.
Initially, SEM-BSE micrographs of corrosion layers show different layers with a stratigraphical sequence, and exhibit differences between chemical composition and phases that form corrosion morphology in samples. To identify the chemical composition of layers, SEM-EDS analysis is performed on each specific layer. Results of SEM-EDS analysis on different corrosion layers are presented in Table 1. The main elements detected in layers are $\mathrm{Cu}$, $\mathrm{Sn}, \mathrm{Cl}$ and $\mathrm{O}$. The $\mathrm{Cu}$ and $\mathrm{Sn}$ amounts are variable and when the amount of $\mathrm{Sn}$ increases, the $\mathrm{Cu}$ decreases. In contrast, chlorine and oxygen were detected at variable levels in almost all layers.

Figure 2 shows corrosion layers of sample HT.33.04 in cross section and SEM-EDS analyses in SEM-BSE image.

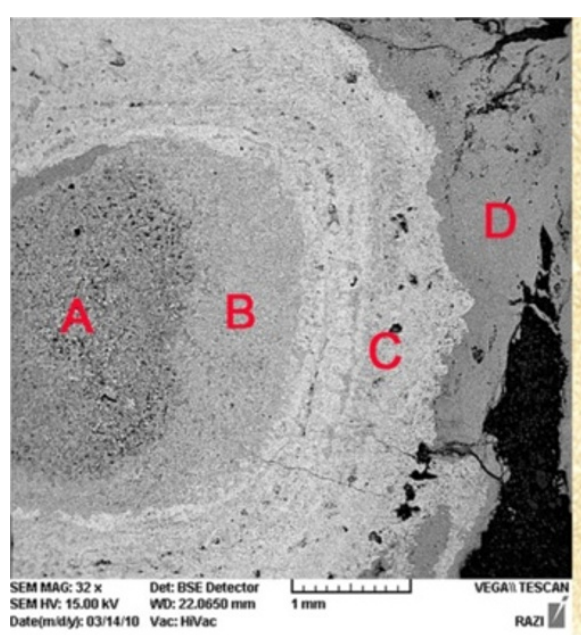

HT.48.04

Figure 4 Cross section and SEM-BSE micrograph of sample HT.48.04 with analysis areas. The white-grayish phase is visible in center this sample. 

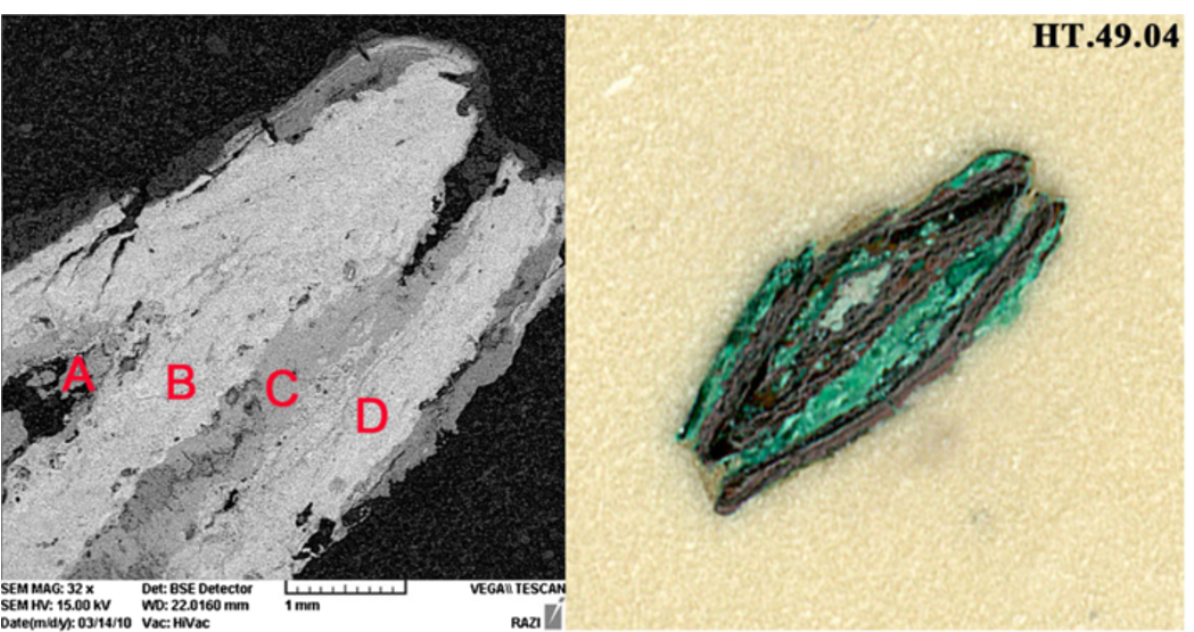

Figure 5 Cross section and SEM-BSE micrograph of sample HT.49.04 with analysis areas. The white-grayish phase is visible in center this sample. This phase has surrounded by red and green corrosion layers.

A white-grayish phase can be observed in center of the cross section which is surrounded by black, red and green corrosion products. SEM-EDS analysis of the white-grayish phase (layer A) proves that it contains high amount of Sn, 76.03\%. Layer B analysis shows a red layer surrounding a central gray one. Unlike, layer A, this layer has high $\mathrm{Cu}$ content (81.39\%) and low $\mathrm{Sn}$ content (12.03\%). Layers C and D are rich in copper and chlorine with variable amounts of $\mathrm{Sn}$. These layers are green in color.

The cross section and SEM-BSE micrograph of sample HT.41.04 is presented in Figure 3. The cross section shows two main layers: the white-grayish layer located in the center of the sample, and the large outer red-brown layer that consist of very finely banded deposits and shows a multilayered structure with representing the alteration of color from pale red to red-brown. Of course, a thin green layer can be observed between the red bands.

SEM-EDS analysis of layers in this sample revealed that inner layer (A) is a tin-rich corrosion product with $54.5 \%$ of Sn beside $9.81 \%$ of $\mathrm{Cu}$. Other elements detected are $\mathrm{Pb}, \mathrm{Cl}, \mathrm{O}, \mathrm{Si}$ and $\mathrm{Al}$. Si and $\mathrm{Al}$ may be come from soil. Layer $\mathrm{B}$ is a green corrosion layer embedded in a banded red-brown corrosion layer and its analysis shows high percent $\mathrm{Cu}$ with some $\mathrm{Sn}$ and $\mathrm{Cl}$ content. Analyses $\mathrm{C}$ and $\mathrm{D}$ are performed on two different area of red massive layer and show corrosion phase with high $\mathrm{Cu}$ content with considerable $\mathrm{Sn}$ content.

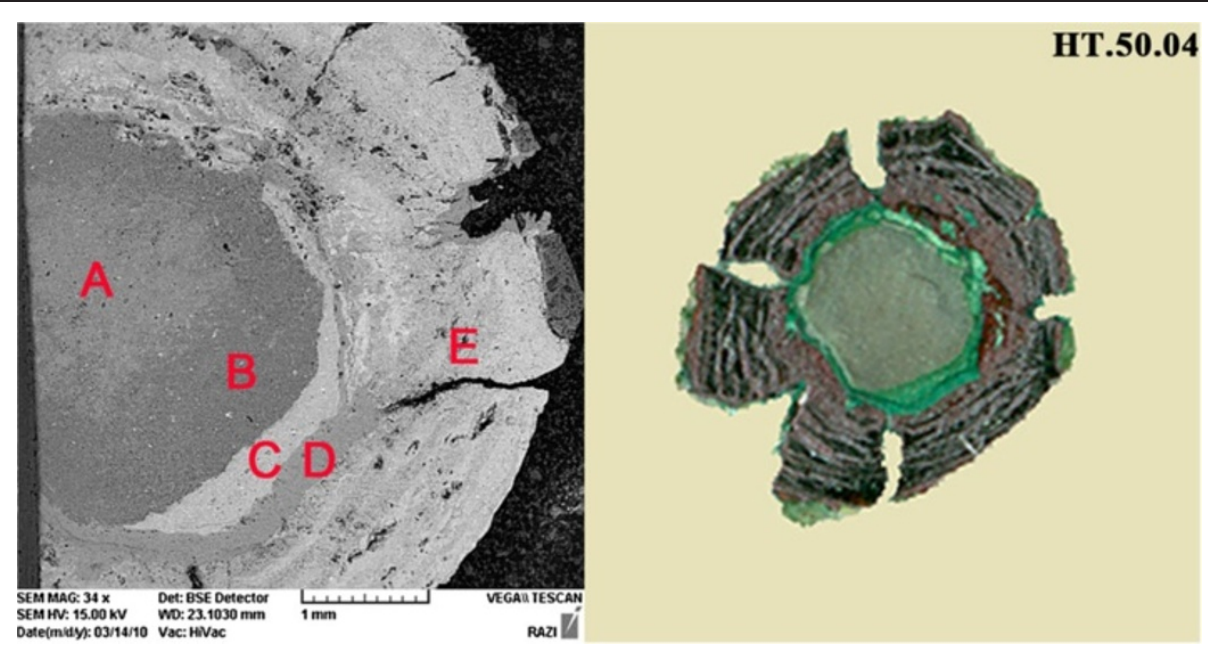

Figure 6 Cross section and SEM-BSE micrograph of sample HT.50.04 with analysis areas. The white-grayish phase is visible in center this sample. The red-brown corrosion layer has some cracks that continued into inner part of sample. 
Table 1 SEM-EDS analysis of different layers in five samples (wt\%)

\begin{tabular}{|c|c|c|c|c|c|c|c|c|c|c|}
\hline & & $\mathrm{Cu}$ & Sn & $\mathrm{Pb}$ & 0 & $\mathrm{Cl}$ & $S$ & $\mathrm{Si}$ & Al & $\mathrm{Mg}$ \\
\hline \multirow[t]{4}{*}{ HT.33.04 } & A & 8.72 & 76.03 & 7.15 & 0.45 & 2.32 & 1.33 & 4.02 & - & - \\
\hline & B & 81.39 & 12.03 & 1.63 & 1.56 & 3.39 & - & - & - & - \\
\hline & $\mathrm{C}$ & 62.47 & 0.19 & - & 12.8 & 24.55 & - & - & - & - \\
\hline & D & 46.43 & 19.03 & - & 2.11 & 18.28 & 8.85 & 5.30 & - & - \\
\hline \multirow[t]{4}{*}{ HT.41.04 } & $A$ & 9.81 & 54.5 & 6.53 & 6.35 & 6.82 & 0.66 & 4.62 & 10.72 & - \\
\hline & B & 71.34 & 13.4 & 9.38 & 0.68 & 5.2 & - & - & - & - \\
\hline & $\mathrm{C}$ & 77.91 & 20.05 & - & 1.57 & 0.47 & - & - & - & - \\
\hline & $D$ & 83.84 & 7.08 & - & 0.65 & 3.03 & - & 5.40 & - & - \\
\hline \multirow[t]{4}{*}{ HT.48.04 } & A & 5.36 & 66.14 & 6.71 & 8.19 & 9.29 & - & 4.32 & - & - \\
\hline & B & 54.57 & 26.42 & 0.28 & 3.43 & 14.56 & 0.74 & - & - & - \\
\hline & $\mathrm{C}$ & 63.38 & 20.99 & 10.75 & 0.55 & 4.33 & - & - & - & - \\
\hline & $D$ & 40.73 & 6.57 & - & 30.08 & 22.62 & - & - & - & - \\
\hline \multirow[t]{4}{*}{ НТ.49.04 } & $A$ & 18.92 & 51.47 & - & 3.44 & 4.77 & 4.50 & 7.92 & - & 8.99 \\
\hline & $\bar{B}$ & 56.75 & 23.61 & 6.25 & 1.22 & 6.62 & 0.91 & 4.64 & - & - \\
\hline & $\mathrm{C}$ & 45.48 & 2.67 & - & 33.35 & 18.5 & - & - & - & - \\
\hline & D & 43.42 & 38.45 & 4.91 & 1.88 & 6.47 & 0.48 & 4.39 & - & - \\
\hline \multirow[t]{5}{*}{ HT.50.04 } & $A$ & 64.68 & 11.16 & - & 2.63 & 21.53 & - & - & - & - \\
\hline & B & 73.33 & 1.21 & - & 1.55 & 23.9 & - & - & - & - \\
\hline & $\mathrm{C}$ & 29.23 & 40.91 & - & 3.33 & 20.82 & - & 5.71 & - & - \\
\hline & D & 29.03 & 4.05 & - & 34.76 & 32.16 & - & - & - & - \\
\hline & $E$ & 75.64 & 16.08 & - & 0.14 & 4.82 & - & 3.31 & - & - \\
\hline
\end{tabular}

The analysis of the corrosion layers in sample HT.48.04 in cross section has performed (A, B, C and D layers respectively) and is shown in Figure 4. The central corrosion phase in this sample has similarities with other white-grayish corrosion layers in the two last bronze samples (HT.33.04 and HT.41.04). It is a Sn rich phase with low $\mathrm{Cu}$ content. Other elements such as $\mathrm{Pb}, \mathrm{O}, \mathrm{Cl}$ and $\mathrm{Si}$ are detected in considerable amounts. Layer $\mathrm{B}$ has considerable $\mathrm{Cl}$ content and shows a mixture of two phases in cross section including red and green corrosion products. Layer $\mathrm{C}$ can be observed as a red banded structure and consists of a $\mathrm{Cu}$-rich phase with detectable $\mathrm{Sn}, \mathrm{Pb}$, and $\mathrm{Cl}$ contact. In contrast, the analyzed green corrosion layer (D) is rich in $\mathrm{Cu}$ and $\mathrm{Cl}$ beside $\mathrm{O}$, and is a copper trihydroxichloride corrosion product.

Figure 5 represents cross section of sample HT.49.04 and the layers in a SEM-BSE micrograph. The central white-grayish phase in this sample is rich in Sn (51.47\%) and $\mathrm{Cu}, \mathrm{O}, \mathrm{Cl}, \mathrm{S}, \mathrm{Si}$ and $\mathrm{Mg}$ are also detected. S, Si and $\mathrm{Mg}$ are elements from the soil that have entered the porous corrosion structure during long-term burial. Analyses of layers B and D show red corrosion products in two areas. The results of SEM-EDS analysis in these layers revealed similarity in composition. Of course, $\mathrm{Cu}$ and $\mathrm{Sn}$ are detected in different quantities in the layers composition but the composition is very similar in the red layers. Layer $\mathrm{C}$ has high $\mathrm{Cl}, \mathrm{Cu}$ and $\mathrm{O}$ content as well as low amount of $\mathrm{Sn}$ that is a result of a copper trihydroxichloride corrosion product.

Figure 6 represents analysis carried out on cross section of sample HT.50.04. Despite of presence of a grayish corrosion layer in the center of cross section, the corrosion layer with highest $\mathrm{Sn}$ content in this sample is layer C. Of course layers A and E have considerable Sn content but copper is the main component for these layers.

The remarkable feature is the high level of $\mathrm{Cl}$ in all layers (about 20\%). Only layer $\mathrm{E}$ has low $\mathrm{Cl}$ content $(4.82 \%)$. On the other hand, in other samples the whitegrayish phase is surrounded by red or black phases whereas in sample HT.50.04, it is surrounded by a green corrosion layer.

The results from all 5 samples show difference a proportion of $\mathrm{Sn}$ and $\mathrm{Cu}$ in layers. The $\mathrm{Sn} / \mathrm{Cu}$ proportion is calculated for all layers. Table 2 presents the ratio of $\mathrm{Sn} / \mathrm{Cu}$ in the different layers of all samples. In layer $\mathrm{A}$, the proportion of $\mathrm{Sn} / \mathrm{Cu}$ is high; with the exception of sample HT.50.04 that this phenomenon can also be observed in layer C. In samples HT.33.04, HT.41.04, HT.48.04 and HT.49.04 this proportion in layer $\mathrm{A}$ is higher than 1 (between 2.72 to 12.33) and shows that layer A (the white-grayish a corrosion phase) has a high Sn content. In other layers it is lower than 1. In sample HT.50.04, the $\mathrm{Sn} / \mathrm{Cu}$ proportion is higher than 1 in layer $\mathrm{C}$. Figure 7 presents the proportion of $\mathrm{Sn} / \mathrm{Cu}$ in all layers.

In other layers, the main element detected is $\mathrm{Cu}$ but also $\mathrm{O}$ and $\mathrm{Cl}$ are detected. Although oxygen plays an important role in the composition of all layers, because of limitations in measuring light elements (such as oxygen) by EDS analysis and low vacuum conditions used in this research, the level of oxygen detected in various layers could not be accurately assessed. In the red brown corrosion layers the main most abundant element detected is $\mathrm{Cu}$. In the green corrosion layers, the $\mathrm{Cl}$ content is considerable beside of copper and this may be because of presence of copper trihydroxichloride compounds (atacamite and paratacamite).

Table $2 \mathrm{Sn} / \mathrm{Cu}$ proportion in corrosion layers of samples based on SEM-EDS results

\begin{tabular}{lccccc}
\hline & A & B & C & D & E \\
\hline HT.33.04 & 8.72 & 0.15 & - & 0.41 & - \\
\hline HT.41.04 & 5.55 & 0.19 & 0.26 & 0.08 & - \\
\hline HT.48.04 & 12.33 & 0.48 & 0.33 & 0.16 & - \\
\hline HT.49.04 & 2.72 & 0.42 & 0.06 & 0.88 & - \\
\hline HT.50.04 & 0.17 & 0.20 & 1.40 & 0.14 & 0.21 \\
\hline
\end{tabular}




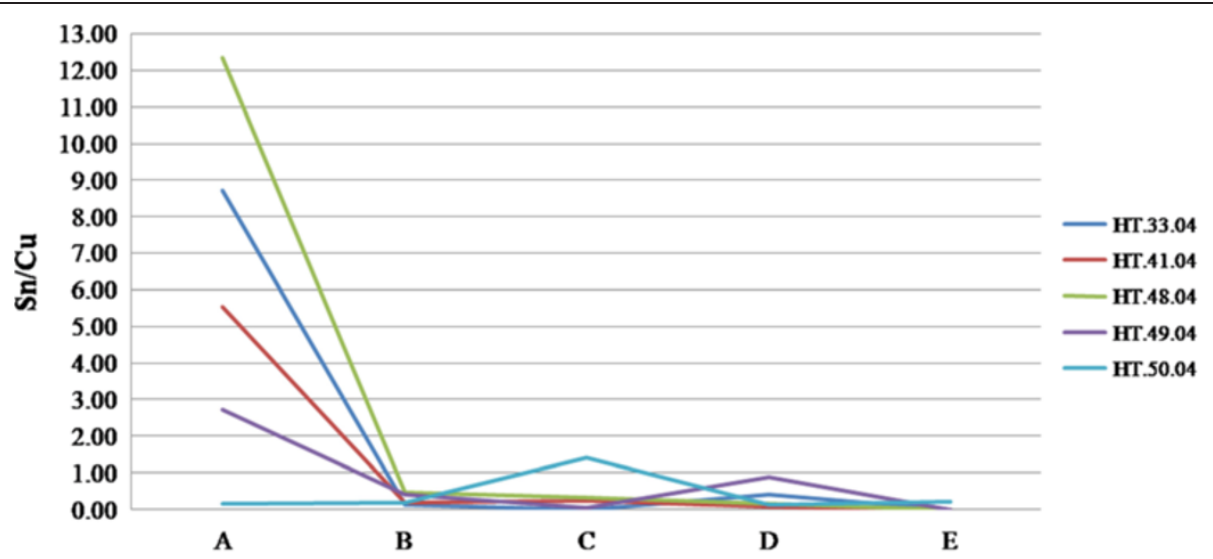

Figure 7 Diagram of $\mathrm{Sn} / \mathrm{Cu}$ proportion in all analyzed layers in five samples. This proportion is more than 1 in layer $\mathrm{A}$ in four samples and $C$ in one sample.

Table 3 Results of XRD analysis of five corroded samples [9]

\begin{tabular}{|c|c|c|c|c|c|c|c|}
\hline & Cuprite & Tenorite & Atacamite & Paratacamite & cassiterite & Nantokite & Quartz \\
\hline HT.33.04 & * & * & * & * & * & - & $*$ \\
\hline HT.41.04 & * & $*$ & $*$ & $*$ & * & - & - \\
\hline HT.48.04 & * & $*$ & $*$ & $*$ & * & - & $*$ \\
\hline HT.49.04 & * & * & * & * & - & - & * \\
\hline НТ.50.04 & * & * & * & * & * & * & - \\
\hline
\end{tabular}

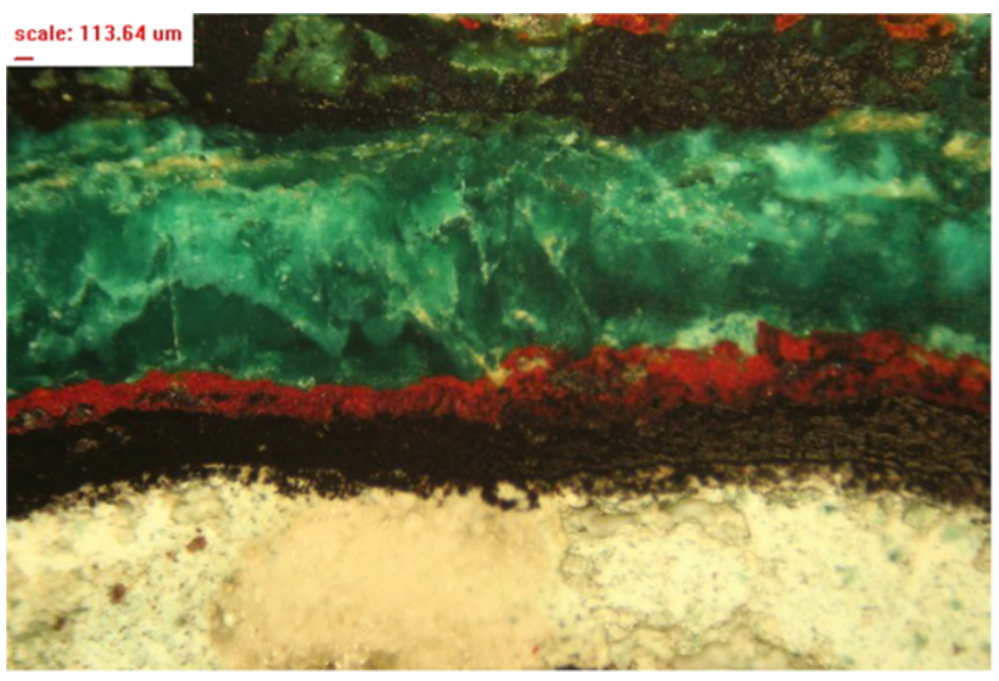

Figure 8 Banded structure of sample HT.33.04. The white-grayish phase is visible in bottom of micrograph that has surrounded with black and red copper oxides. The copper trihydroxichlorides layer is visible above the oxide layer. 


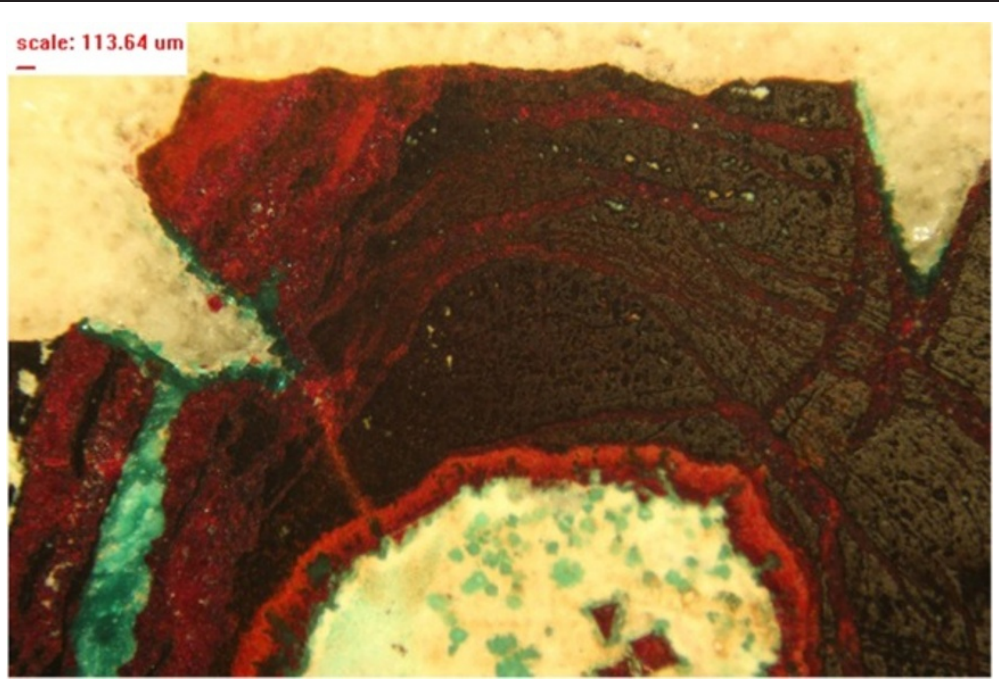

Figure 9 Microstructure of sample HT.41.04. The white-grayish phase is visible in bottom of micrograph that has surrounded with red copper oxides. The banding phenomenon is apparently visible in cuprite layer. The tin rich layer has some green phases as scattered islands.

In fact, the chemical composition of the pale-green layer in the samples shows a $\mathrm{Cl}$ rich phase with high $\mathrm{Cu}$ content. The black and red layers also contain very high amount of $\mathrm{Cu}$. As noted above, only in sample HT.50.04, is the $\mathrm{Cu}$ content high in the central layers. The XRD analysis on these samples proves the presence of these corrosion products in the sample. The XRD analyses were performed by X-ray diffraction, D8 ADVANCE model (Bruker axs, Germany), CuKa source with wavelength $1.54 \AA$, at the Central Laboratory of the University of Isfahan, Iran [9]. The XRD results are presented in Table 3. Based on XRD and SEM-EDS results, the red and black phases may be copper oxides such as cuprite $\left(\mathrm{Cu}_{2} \mathrm{O}\right)$ and tenorite $(\mathrm{CuO})$ [2] and the pale-green phase consist of copper trihydroxichlorides such as atacamite/paratacamite $\left(\mathrm{Cu}_{2}(\mathrm{OH})_{3} \mathrm{Cl}\right)$ [12] Nantokite $(\mathrm{CuCl})$ has been identified as a corrosion product in sample HT.50.04. With regard to the high percentage of chlorine and copper in the inner phase in this sample, nantokite may be an important corrosion product in central layers (A and B) in sample HT.50.04.

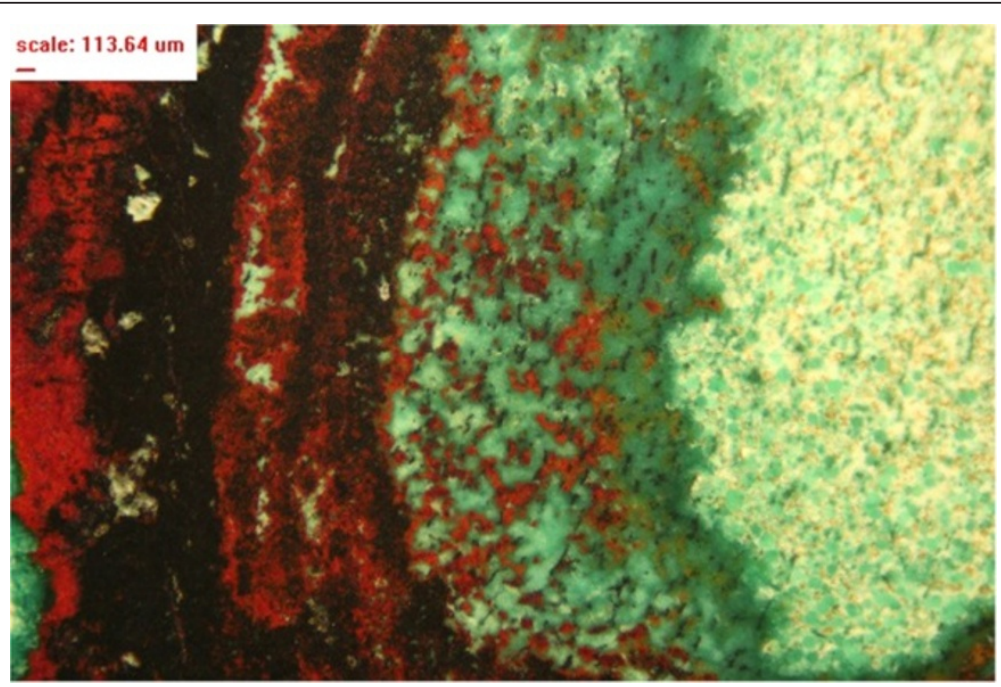

Figure 10 Banded structure of sample HT.48.04. The white-grayish phase is visible in right of micrograph. The phase located in center of picture and next to central phase, is a mixture of cuprite and copper trihydroxichlorides. The banding is visible in cuprite at left. 


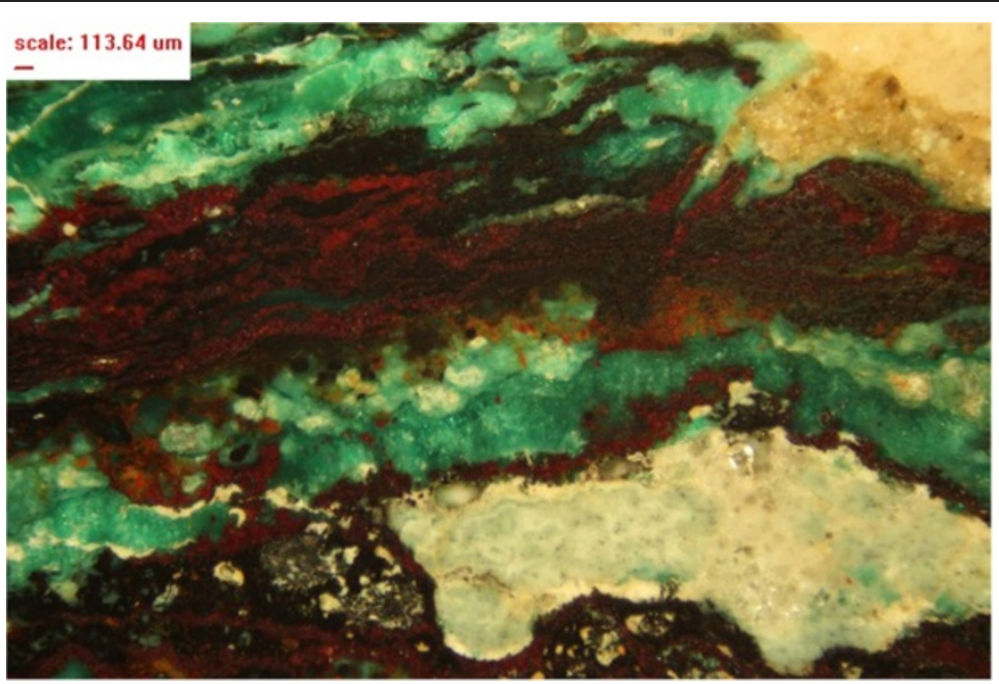

Figure 11 Microstructure of sample HT.49.04. The white-grayish phase is visible in bottom right of micrograph. The banded layers of cuprite and copper trihydroxichlorides are surrounded the inner corrosion layer.

Based on analytical results and microscopy, the corrosion mechanism in the samples is bronze disease. The presence of chlorine in the burial environment may cause reaction of copper with it and formation of cuprous chloride. The first reaction product is nantokite $(\mathrm{CuCl})$. Nantokite may occur in different areas of copper alloy artefacts: from underneath of cuprite layer to the inner part of a corroded one $[13,14]$. Bronze disease, sometimes, is used for the interpretation of the occurrence of pale green powdery patches and pits after excavation of archaeological copper alloys [1]. In fact, this process is the reaction of copper with chlorine in presence of moisture and oxygen that causes the formation of copper trihydroxichlorides. This process will continue (if moisture is available) until all metallic copper converts to copper trihydroxichlorides [1,2,13], based on following equation [2]:

$$
4 \mathrm{CuCl}+\mathrm{O}_{2}+4 \mathrm{H}_{2} \mathrm{O} \rightarrow 2 \mathrm{Cu}_{2}(\mathrm{OH})_{3} \mathrm{Cl}+2 \mathrm{H}^{+}+2 \mathrm{Cl}^{-}
$$

The presence of tin-rich phase in the center of samples is due to an identified process namely decuprification or selective dissolution of $\mathrm{Cu}$ [15-18]. It occurs because of $\mathrm{Cu}$ dissolution in corrosion of bronze artefacts in various

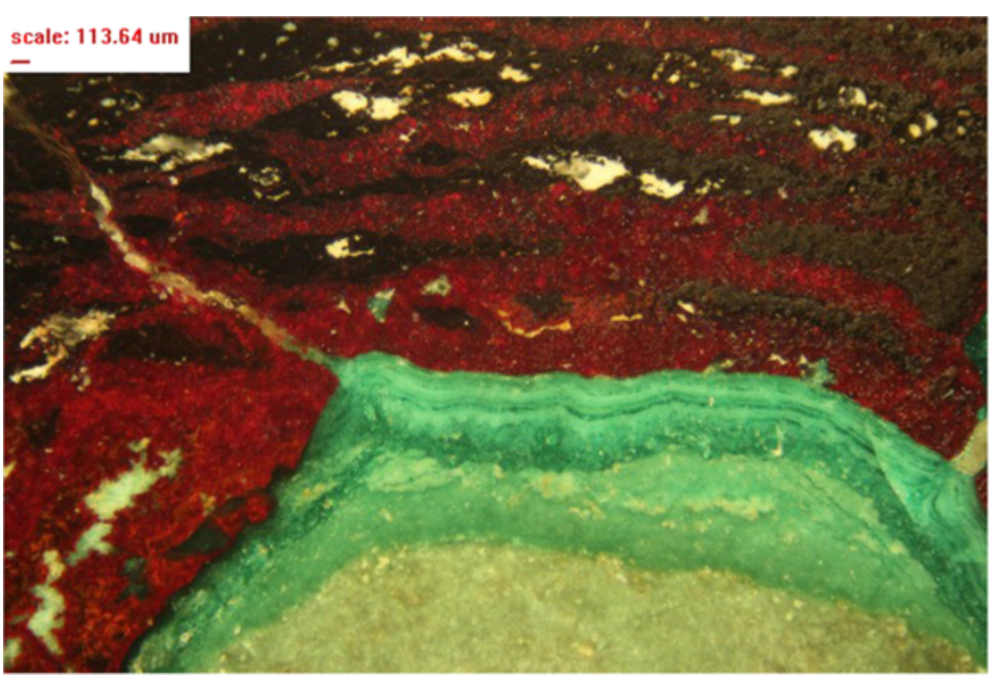

Figure 12 Microstructure of sample HT.50.04. The grayish phase is visible in bottom of micrograph that surrounded with a banded layer of copper trihydroxichlorides. The banding phenomenon is visible in cuprite. 
environments such as soil. Some $\mathrm{Cu}$ will leach from metallic structures with internal oxidation of Sn. The dissolved $\mathrm{Cu}$ will react with soil anions such as chloride and carbonate, and will deposit in external part of the artefact or its surface. The composition of redeposited corrosion compound on the surface of artefact is related to the nature of soil soluble anions and their reactivity $[15,16]$. This phenomenon is the main reason of corrosion morphologies appearing in archaeological bronzes in soil $[9,15,16]$. In samples studied, the dissolved $\mathrm{Cu}$ has reacted with $\mathrm{Cl}$ that has led to formation of copper trihydroxichlorides. The central phase consists of $\mathrm{SnO}_{2}$ (cassiterite) with some $\mathrm{Cu}$ compounds such as cuprite $\left(\mathrm{Cu}_{2} \mathrm{O}\right)$ or nantokite $(\mathrm{CuCl})$ [9]. The presence of some elements such as $\mathrm{Al}, \mathrm{Mg}, \mathrm{Si}$ and $\mathrm{S}$ in the corrosion layers may be due to immigration from the soil to the porous corrosion layers.

The corrosion layers represent a multilayered structure that can be observed in optical microscopy (Figures 8, 9, 10, 11 and 12). These multilayered corrosion products could be interpreted by a banding phenomenon that has been observed in excavated bronzes previously $[19,20]$. The banding has relations with environmental changes in burial environment such as seasonal temperature fluctuations, rainfall fluctuations, change in soil corrosivity as well as other processes as a result of interdiffusion of metallic components and soil salts present in soil water. These changes cause the deposition of insoluble corrosion products such as cuprite, malachite, copper trihydroxichlorides or cassiterite in separated or banded layers. The banded structure in archaeological copper alloys has referred to Liesegang Phenomena [19].

It is notable that there is no evidence of banding in the central white-grayish cassiterite layer in the five samples studied. The microstructure of the central layer (phase) shows a pseudomorphic replacement of original microstructure of the alloy such as the ghost structure of twinned and recrystallized grains in sample HT.48.04 (Figure 13) [19-21].

This microstructure can be interpreted by selective dissolution of copper and internal oxidation and in situ deposition of tin that causes to replacement of metallurgical structure in corrosion product $[15,21]$.

\section{Conclusion}

To characterize corrosion layers in some corroded archaeological bronze artefacts from southwest Iran, a micro-stratigraphical approach based on SEM-EDS and OM methods has established. Observations show a multilayer structure in cross section consisting of a tin rich phase in center of samples, pale green layer with high $\mathrm{Cl}$ content that appears as one or more layers in various parts of the cross-section and a massive red layer that in some cases is observed with together a

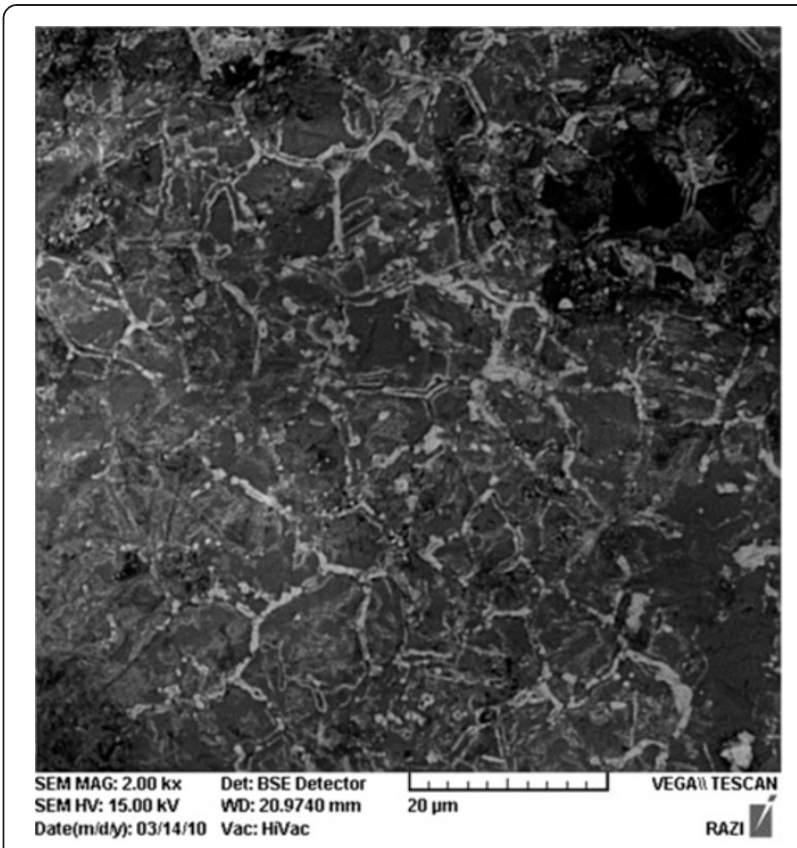

Figure 13 SEM-BSE micrograph of central white-grayish tin rich corrosion phase of sample HT.48.04 that represents ghost structure of recrystallized and twinned grains of original bronze alloy that has replaced by corrosion products pseudomorphically.

black layer. These last layers contain high amounts of copper and may be copper oxides. This corrosion morphology can relate to the occurrence of bronze disease as well as selective dissolution of copper that has caused increase in volume and formation of a tin rich white-grayish phase in center of the corroded metal. This micro-stratigraphical study helps us to better understand corrosion mechanism and morphology in bronze artefacts as well as their conservation condition in the archaeological bronze collection of Haft Tappeh Middle Elamite site.

\section{Competing interests}

The authors declare that they have no competing interests.

\section{Authors' contributions}

$\mathrm{OO}$ performed the analytical work and OM observations. SMA performed the Optical Microscopy observations and participated in the research design. HA helped to draft the manuscript and participated in the research design. PD participated in analytical work and helped to draft the manuscript. All authors read and approved the final manuscript.

\section{Acknowledgement}

The authors are thankful to Behnam Rahmani from Razi Metallurgical Research Center, Tehran for his help to carry out SEM-EDS analyses, and Atefeh Shekofteh, Mehri Qobadi and Mohammad Mortazavi from the Art University of Isfahan for their ideas and helps to perform the Optical Microscopy observations. 


\section{Author details}

${ }^{1}$ Faculty of Conservation, Art University of Isfahan, Isfahan, Iran. ${ }^{2}$ Faculty of Material Science and Engineering, Sharif University of Technology, Tehran, Iran.

Received: 5 February 2013 Accepted: 16 July 2013

Published: 24 July 2013

\section{References}

1. Selwyn LS: Corrosion of metal artifacts in buried environments, ASM handbook. Vol. 13C. Corrosion: Environments and Industries; 2006:306-322.

2. Scott DA: Copper and Bronze in Art: Corrosion, Colorants and Conservation. Los Angeles: Getty Conservation Institute Publications; 2002.

3. Cushing D: Principles of corrosion applicable to ancient metals and methods of identifying corrosion products. Boston: Application of Science in the Examination of Works of Art; 1967:53-65.

4. Ingo GM, De Caro T, Riccucci C, Khosroff S: Uncommon corrosion phenomena of archaeological Bronze alloys. Applied Phys A Mat Sci Proc 2006, 83:581-588.

5. Ingo GM, Angelini E, Bultrini G, Calliari I, Dabala M, De Caro T: Study of long-term corrosion layers grown on high-tin leaded Bronzes by means of the combined use of GDOES and SEM + EDS. Surf Inter Anal 2002, 34:337-342

6. McCann LI, Trentelman K, Possley T, Golding B: Corrosion of ancient Chinese Bronze money trees studied by Raman microscopy. J Raman Spect 1999, 30:121-132.

7. Robbiola L, Fiaud C: Corrosion structures of long-term burial Cu-Sn alloys: influence of the selective dissolution of copper. Editions de la Revue de Métallurgie 1993, 6:157-162.

8. Reale R, Plattner SH, Guida G, Sammartino MP, Visco G: Ancient coins: cluster analysis applied to find a correlation between corrosion process and burial soil characteristics. Chem Central J 2012, 6(Suppl 2):S9.

9. Oudbashi O, Emami SM: A note on the corrosion morphology of some Middle Elamite Copper alloy artefacts from Haft Tappeh, Southwest Iran. Stud Conserv 2010, 55:20-25.

10. Oudbashi O, Emami SM, Davami P: Bronze in archaeology: a review of archaeometallurgy of Bronze in ancient Iran. In Copper alloys - early applications and current performance - enhancing processes. Edited by Collini L, Rijeka: InTech; 2012:147-174. http://cdn.intechopen.com/pdfs/ 30478/InTech-Bronze_in_archaeology_a_review_of_the_archaeometallurgy_ of_bronze_in_ancient_iran.pdf.

11. Negahban EO: Excavations at Haft Teppe, Iran, university museums monograph 70. Philadelphia: University of Pennsylvania Museum Publications; 1991.

12. Scott DA: A review of copper chlorides and related salts in Bronze corrosion and as painting pigments. Stud Conserv 2000, 45:39-53.

13. Scott DA: Bronze disease: a review of some chemical problems and the role of relative humidity. JAIC 1990, 29:193-206.

14. MCNeil MB, Little BJ: The Use of mineralogical data in interpretation of long-term corrosion processes: sulfiding reaction. JAIC 1999, 38(2):186-199.

15. Piccardo $P$, Mille $B$, Robbiola L: Tin and copper oxides in corroded archaeological Bronzes. In Corrosion of metallic heritage artefacts, investigation, conservation and prediction for long-term behaviour, European federation of corrosion publications, No. 48. Edited by Dillmann P, Beranger G Piccardo P, Matthiesen H. Cambridge: Woodhead Publishing Limited: CRC Press: 2007:239-262.

16. Robbiola L, Blengino JM, Fiaud C: Morphology and mechanisms of formation of natural patinas on archaeological Cu-Sn alloys. Corros SC 1998, 40:2083-2111.

17. Robbiola L, Portier R: A global approach to the authentication of ancient Bronzes based on the characterization of the alloy-patina-environment system. J Cult Herit 2006, 7:1-12.

18. Mabille I, Bertrand A, Sutter EMM, Fiaud C: Mechanism of dissolution of a Cu-13Sn alloy in low aggressive conditions. Corros Sci 2003, 45:855-866.

19. Scott DA: Periodic corrosion phenomena in Bronze antiquities. Stud Conserv 1985, 30:49-57.
20. Sandu I, Ursulescu N, Sandu IG, Bounegru O, Sandu ICA, Alexandru A: Pedological stratification effect of corrosion and contamination products on Byzantine Bronze artefacts. Corros Eng Sci Technol 2008, 43(3):256-266.

21. Oddy WA, Meeks ND: Unusual phenomena in the corrosion of ancient bronzes. in Science and Technology in the Service of Conservation. In International Institute for Conservation of Historic and Artistic Works. Edited by Brommelle NS, Thomson G. London: IIC Washington Congress; 1982:119-124.

doi:10.1186/2050-7445-1-21

Cite this article as: Oudbashi et al:: Micro-stratigraphical investigation on corrosion layers in ancient Bronze artefacts by scanning electron microscopy energy dispersive spectrometry and optical microscopy. Heritage Science 2013 1:21.

Publish with ChemistryCentral and every
scientist can read your work free of charge
"Open access provides opportunities to our
colleagues in other parts of the globe, by allowing
anyone to view the content free of charge."
W. Jeffery Hurst, The Hershey Company.
- available free of charge to the entire scientific community
- peer reviewed and published immediately upon acceptance
- cited in PubMed and archived on PubMed Central
- yours - you keep the copyright
Submit your manuscript here:
http://www.chemistrycentral.com/manuscript/

